\title{
CROSSTALK BETWEEN BRAIN-DERIVED NEUROTROPHIC FACTOR AND N-METHYL-D-ASPARTATE RECEPTOR SIGNALING IN NEURONS
}

\author{
Danko D. Georgiev, Hideo Taniura, Yuki Kambe, and Yukio Yoneda \\ Laboratory of Molecular Pharmacology, Division of Pharmaceutical Sciences, Kanazawa University \\ Graduate School of Natural Science and Technology, Kanazawa, Ishikawa 920-1192, Japan
}

Glutamate is the major excitatory neurotransmitter in brain exerting prosurvival effect on neurons via $N$-methyl-D-aspartate receptor (NMDAR) signaling under physiological conditions. However in pathological circumstances such as ischemia, NMDARs might have proapoptotic excitotoxic activity. In contrast brain-derived neurotrophic factor (BDNF) signaling via tropomyosinrelated receptor kinase $B$ (TrkB) has been largely considered to promote neuronal differentiation, plasticity and survival during normal development, and protect neurons in pathophysiological conditions antagonizing the NMDAR-mediated excitotoxic cell death. In this review we summarize recent evidence for the existent crosstalk and positive feedback loops between the BDNF and NMDAR signaling and point out some of the important specific features of each signaling pathway.

Biomed Rev 2008; 19: 17-27.

Key words: NMDA receptor, BDNF, neurotrophins

\section{INTRODUCTION}

Neurotransmitters and growth factors promote growth, survival and differentiation of neurons in central nervous system. Moreover, in adult brain they participate in synaptic signaling and synaptic remodeling, which underlie learning and memory formation (1). While N-methyl-D-aspartate receptor (NMDAR) signaling is physiologically essential for neuronal survival (2), it might have excitotoxic proapoptotic effect under pathophysiological conditions such as ischemia (3-5). In contrast brain-derived neurotrophic factor (BDNF) is considered to have predominantly prosurvival activity both in health and disease and its tropomyosin-related receptor kinase B or tyrosine receptor kinase B (TrkB) signaling is a major protective mechanism against ischemic injury (6). In this review we focus on the recent progress made in elucidating the mechanisms for crosstalk between BDNF and NMDAR prosurvival signaling pathways.

\section{CALCIUM AS A SECOND MESSENGER}

NMDAR-mediated $\mathrm{Ca}^{2+}$ increase

Glutamate-mediated trophic effects in the brain depend on the type of receptors, intensity of the signal, and the signaling context (7-10). Undoubtedly one of the most intricate signaling pathways involves the NMDARs, which are excitatory heterotetramer channels highly permeable for $\mathrm{Ca}^{2+}$ ions, require the coagonist glycine for proper function and are subject to

Received 2 October 2008, accepted 7 November 2008.

Correspondence and reprint request to Dr Danko Georgiev, Department of Psychiatry and Neurobiology, Graduate School of Medical Science, Kanazawa University, 13-1 Takaramachi, Kanazawa, Ishikawa 920-8641, Japan.

E-mail: danko@med.kanazawa-u.ac.jp 
voltage-dependent block by physiological $\mathrm{Mg}^{2+}$ concentrations. Blockade of normal NMDAR function induces apoptotic cell death of cortical and thalamic neurons (11-13). Currently there are seven NMDAR subunits known: NR1 (ל1), NR2A-D ( $11-4)$ and NR3A-B $(14,15)$. For five of the subunits (NR1, NR2B, NR2C, NR2D and NR3A) are reported splice variants. Most native NMDARs are assembled of two glycine-binding NR1 and two glutamate-binding NR2 subunits. NMDARs are therefore NR2-containing receptors in which NR1/NR2 het- erodimers (Fig. 1) appear to be the functional unit (16). NR3 subunit containing NMDARs are expressed at late postnatal stages of CNS neuronal development (17) and could be either NR1/NR2/NR3 heteromeric channels with decreased $\mathrm{Ca}^{2+}$ permeability (18), or excitatory NR1/NR3 glycine receptors, which are insensitive for glutamate or NMDA (19). Activation of NMDARs leads to direct $\mathrm{Ca}^{2+}$ influx, and subsequent activation of $\mathrm{Ca}^{2+}$-dependent protein kinases or protein phosphatases, which act as intracellular messengers.

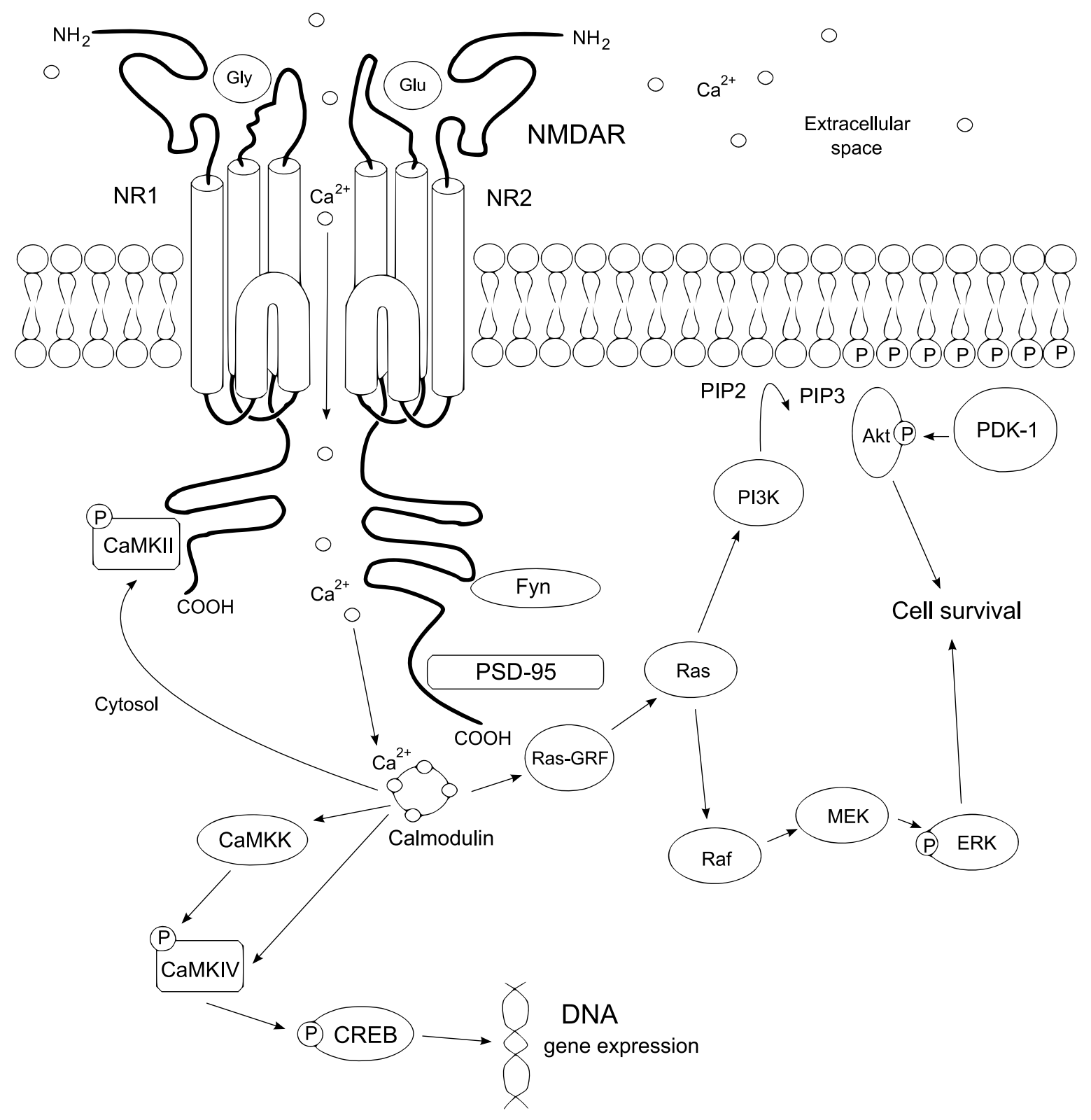

Figure 1. NMDAR signaling - triggering of $\mathrm{Ca}^{2+} / \mathrm{CaMK}$, PI3K/Akt and Ras/MEK/ERK pathways. Abbreviations: ERK, extracellular signal-regulated kinase; NMDAR, $N$-methyl-D-aspartate receptor; $p C R E B$, phosphorylated cAMP response elementbinding protein; PDK-1, phosphoinositide-dependent kinase-1; PI3K, phosphatidylinositol-3 kinase; PIP2, phosphatidylinositol 4,5 bisphosphate; PIP3, phosphatidylinositol-3,4,5-trisphosphate. 


\section{TrkB-mediated $\mathrm{Ca}^{2+}$ increase}

BDNF exerts its effect through TrkB that has tyrosine kinase activity triggering several distinct biochemical pathways, amongst which is the activation of $\gamma$-isoform of phospholipase C (PLC- $\gamma)$. PLC- $\gamma$ further cleaves phosphatidylinositol-4,5bisphosphate (PIP2) to produce diacylglycerol (DAG) and inositol-1,4,5-trisphosphate $\left(\mathrm{IP}_{3}\right)$, the latter binding to $\mathrm{IP}_{3}$ receptors ( $\mathrm{IP}_{3} \mathrm{Rs}$ ) releasing $\mathrm{Ca}^{2+}$ from the endoplasmic reticulum. However, TrkB receptor activation also potentiates the $\mathrm{Ca}^{2+}$ influx through NMDARs via NR1 subunit phosphorylation (20) or NR2B subunit phosphorylation (21). It has been also shown that TrkB, Fyn and NR2B subunit form a multimeric protein complex and the extent of TrkB-Fyn-NR2B protein interaction increases in behavioral tests for spatial learning (22).

\section{THE CALMODULIN/CAMK PATHWAY}

\section{NMDAR-mediated calmodulin/CaMK activation}

Glutamate binding to NMDARs in the presence of the coagonist glycine directly opens the ion channel pore leading to $\mathrm{Ca}^{2+}$ influx from the extracellular space. $\mathrm{Ca}^{2+}$ ions then activate calmodulin, which is a small, acidic protein with a molecular mass $\sim 17 \mathrm{kDa}$. It contains four EF-hand motifs, each of which binds a $\mathrm{Ca}^{2+}$ ion. $\mathrm{Ca}^{2+} /$ calmodulin complex further activates $\mathrm{Ca}^{2+} /$ calmodulin-dependent protein kinase kinase (CaMKK), which phosphorylates $\mathrm{Ca}^{2+} /$ calmodulin-dependent protein kinases I and IV (CaMKI/IV), but not CaMKII, which is regulated by autophosphorylation. Though it did not seem clear why both the enzyme (CaMKK) and its substrates (CaMKs) both require binding of $\mathrm{Ca}^{2+} /$ calmodulin (23), now there is an evidence that CaMKK phosphorylates and activates protein kinase $\mathrm{B}(\mathrm{PKB})$ triggering an alternative cascade pathway, and by this, has an anti-apoptotic effect on the cell (24). CaMK has several isoforms, of which CaMKIV is predominantly nuclear, while CaMKII may exist in the cytoplasm or nucleus, depending on the isoform mix of the heteromultimerized holoenzyme (25). In postsynaptic space CaMKII mediates long-term potentiation (LTP), which underlies memory storage and formation. Interestingly, CaMKII activity is regulated via docking to NR1 and NR2B subunits of NMDARs, where it might be locked in an active conformation $(26,27)$. Autophosphorylated CaMKII $\alpha$ binds directly to NMDARs in the postsynaptic density, and phosphorylates NR2B subunits at $\mathrm{S}^{1303}$, which leads to NR2B NMDAR desensitization (28). In cultured rat cerebellar granule neurons the pharmacological intervention either with CaMKII/IV inhibitor KN62 (29) or calmodulin inhibitor W13 (30) blocked the protective effects of NMDA against exposure to low level $\mathrm{K}^{+}$medium. Both CaMKII and CaMKIV might phosphorylate CREB at $\mathrm{S}^{133}$ thus enhancing target gene expression such as BDNF (31). Moreover, it has been suggested that BDNF expression via $\mathrm{pCREB}$ is due to synaptic NMDAR activation, and not to extrasynaptic NMDAR function (32). Although initially it has been proposed that extrasynaptic NMDARs are NR2B, while synaptic are NR2A, and this subunit composition difference might explain the different roles of synaptic and extrasynaptic NMDARs in cell survival $(32,33)$, currently there is evidence that NR2B receptors in synapses have prosurvival function, while NR2B receptors in extrasynaptic locations mediate cell death. This has been shown in rat primary hippocampal neuronal cultures, at an early developmental stage where the immature neurons express NR2B NMDARs both in synaptic and extrasynaptic locations, but do not express NR2A (8). Interestingly, it was shown that $65 \%$ of synaptic NMDARs are exchanged with extrasynaptic ones in less than $7 \mathrm{~min}$ via lateral diffusion process $(34,35)$, which implies that the supramolecular organization and recruitment of specific transduction pathways to synaptic NMDARs is critical for NMDA-mediated survival.

\section{TrkB-mediated calmodulin/CaMK activation}

BDNF is a peptide with a molecular mass $\sim 13 \mathrm{kDa}$, which forms stable homodimers that are secreted in both constitutive and regulated pathways. Binding of BDNF homodimers to TrkB receptors triggers ligand-induced receptor dimerization and autophosphorylation of tyrosine residues in the intracellular kinase domain (Fig.2), and at the $\mathrm{Y}^{515}$-Shc and $\mathrm{Y}^{816}$-PLC $\gamma$ sites (36). Activation of PLC $\gamma$ leads to $\mathrm{IP}_{3}$-dependent release of $\mathrm{Ca}^{2+}$ from the internal stores with subsequent calmodulin and CaMKII or CaMKIV activation.

\section{THE PI3K/AKT PATHWAY}

\section{NMDAR-mediated PI3K/Akt activation}

$\mathrm{Ca}^{2+}$ influx through the NMDAR receptor leads to activation of the GTP/GDP exchange factor RasGRF via calmodulin (37), with subsequent activation of Ras having diverse intracellular effects amongst which is activation of PI3K $(38,39)$. Phosphatidylinositol-3 kinase (PI3K) phosphorylates phosphatidylinositols of the cell membrane, thus generating phosphatidylinositol-3,4,5-trisphosphate (PIP3) from phosphatidylinositol-4,5-bisphosphate (PIP2). PIP3 at the cell membrane recruits protein kinases such as PKB (known also as Akt kinase) and phosphoinositide-dependent kinase-1 (PDK1), which bind with their pleckstrin homology $(\mathrm{PH})$ domain to 


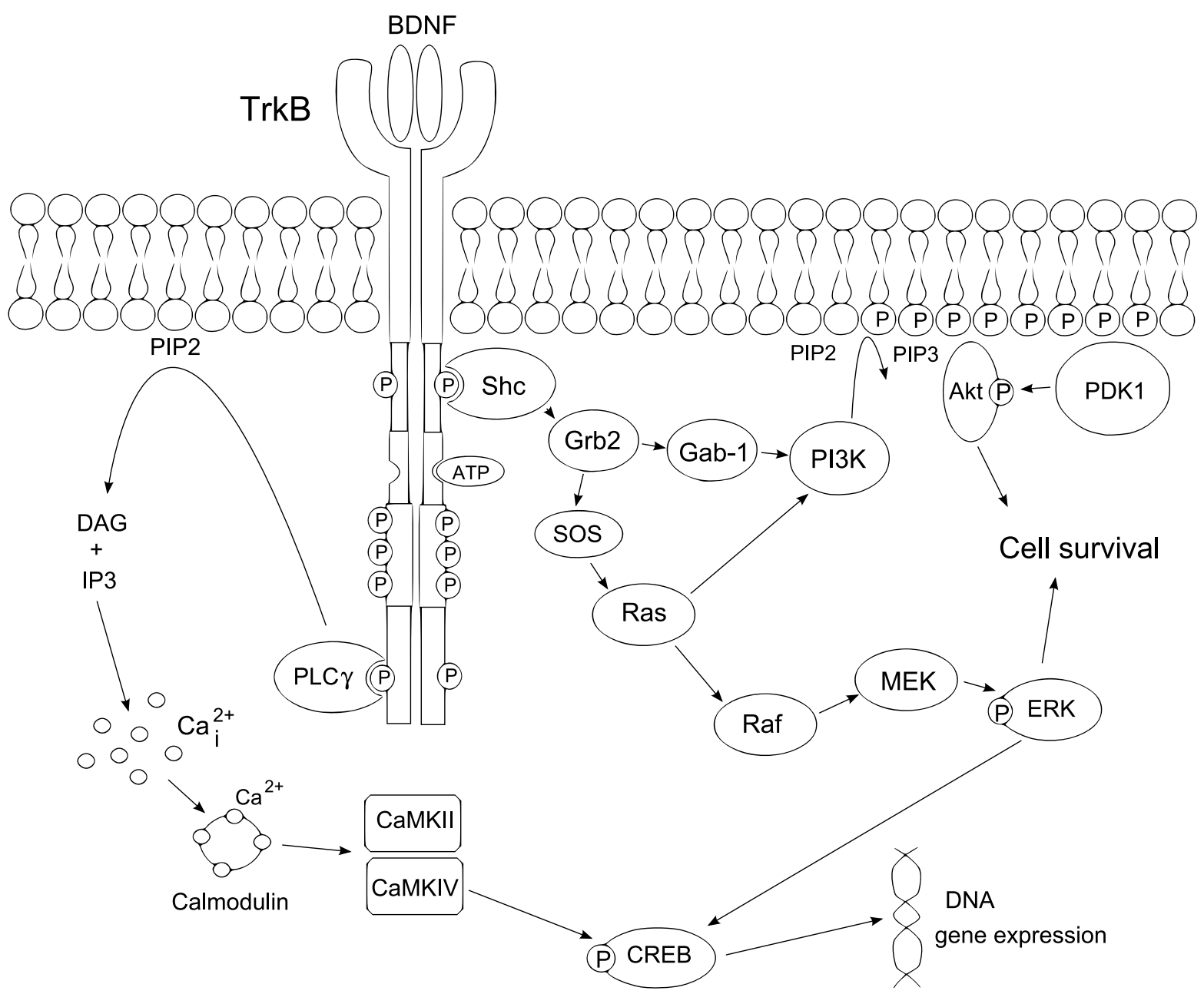

Figure 2. BDNF/TrkB signaling - triggering of $\mathrm{Ca}^{2+} / \mathrm{CaMK}$, PI3K/Akt and Ras/MEK/ERK pathways. Abbreviations: BDNF, brain-derived neurotrophic factor; DAG, diacylglycerol; Grb2, growth factor receptor bound protein-2; IP3, inositol-1,4,5trisphosphate; PLC, phospholipase C.

PIP3 (40). Activation of PKB/Akt requires the phosphorylation by PDK-1, which is regulated by the conformation of PKB/ Akt. Specifically, the engagement of the PH domain on the membrane by binding PIP3 relieves autoinhibition of the active site, allowing PDK- 1 to access $\mathrm{T}^{308}$ on the PKB/Akt activation loop (41). Though PDK-1 is a major activator of PKB/ Akt, there is a crosstalk with the calmodulin/CaMK pathway since both CaMK and CaMKK phosphorylate PKB/Akt (42). Active $\mathrm{PKB}$ then promotes growth and protein translation via phosphorylation of mTOR (43), and it was shown that NMDAR mediated neuroprotection requires both transcription activation and synthesis of new proteins (44). Moreover, PKB/ Akt suppresses apoptosis via triggering phosphorylation of Bad, caspase 9, GSK-3 $\beta$ (45) or dephosphorylation of MKL3,
JNK and c-Jun (46). The importance of PI3K/Akt signaling in NMDAR pro-survival activity has been shown in cultured rat cerebellar granule neurons, where PI3K inhibition with either LY294002 (47) or wortmanin (48) reduced NMDA protection against apoptosis in low level $\mathrm{K}^{+}$medium (49).

\section{TrkB-mediated PI3K/Akt activation}

BDNF activation of TrkB, leads to phosphorylation of the $\mathrm{Y}^{515}$-Shc receptor site that recruits Shc protein and subsequent activation of Grb2, Gab-1 and PI3K (50). PI3K then might mediate activation of $\mathrm{PKB} / \mathrm{Akt}$, which activates the kinase mTOR (Fig. 3). mTOR further phosphorylates eIF4E-binding proteins (4E-BPs), which leads to eukaryotic initiation factor 4E (eIF4E) liberation and local spine translation of CaMKII, 


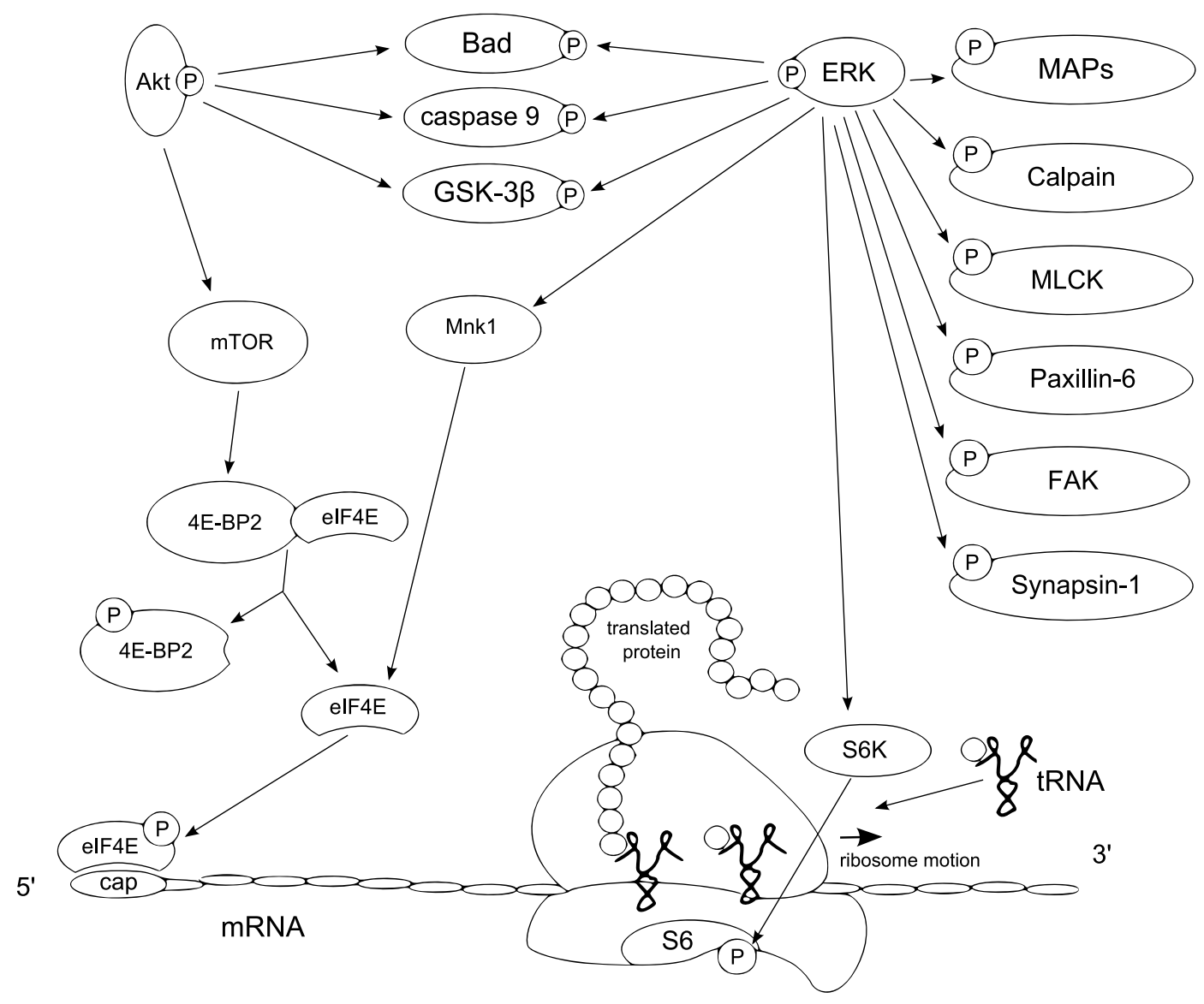

Figure 3. Akt/ERK control of protein translation and cellular activities (cytoskeletal dynamics, releasable pool of synaptic vesicles, apoptosis, etc.). Abbreviations: 4E-BPs, eIF4E-binding proteins; eIF4E, eukaryotic initiation factor 4E; FAK, focal adhesion kinase; MAPs, microtubule-associated proteins; MLCK, myosin light polypeptide kinase; mRNA, messenger RNA; tRNA, transport RNA.

Arc (activity-regulated cytoskeletal-associated protein), LIMK1 and GluR1, mediating the BDNF trophic effect on dendritic spines (51). Additional bifurcation of the biochemical pathway occurs at Grb2, which might activate SOS, followed by Ras, Raf, MEK, and ERK-1/2 activation (50). Mutations in TrkB $\mathrm{Y}^{515}$-Shc receptor site impair both PI3K and MEK signaling pathways, thereby compromising neuronal survival and local axon growth (52).

\section{THE ERK-1/2 PATHWAY}

\section{NMDAR-mediated ERK activation}

NMDAR activation activates Ras via $\mathrm{Ca}^{2+} /$ calmodulin-dependent activation of Ras-GRF (39) or enhancement of nitric oxide (NO) production by neuronal NO synthase (nNOS), which is anchored to NMDARs via PSD-95 (53). Ras has a critical cysteine group which is nitrosylated and thus mediates the $\mathrm{NO}$ mediated activation (54). Except for activation of PI3K, Ras further activates Raf (also known as mitogen-activated protein kinase kinase kinase, MAPKKK), MEK-1/2 (also known as mitogen-activated protein kinase kinase, MAPKK), and ERK$1 / 2$ (also known as mitogen-activated protein kinase, MAPK) (55). Recent evidence shows however that NMDAR-mediated ERK activation requires a specific coupling of NMDAR, Src and ERK, via caveolin-1, which helps the assembly of the signaling cascade within the neuronal lipid rafts (56). The organization of supramolecular complexes for NMDAR/ ERK signal transduction explains the interesting observation that synaptic NMDARs activate ERK, while extrasynaptic 
NMDARs trigger ERK shut off pathway $(57,58)$. Activation of ERK-1/2 leads to CREB phosphorylation, expression of prosurvival/anti-apoptotic target genes (59) and activation of DNA repair enzymes (60). Other important intraneuronal targets phosphorylated by ERK-1/2 are the microtubule-associated proteins (MAPs), which participate in building the neuronal microtubule cytoskeleton (61). ERK-1/2 also phosphorylates myosin light polypeptide kinase (MLCK), calpain, paxillin-6 and focal adhesion kinase (FAK) that play important role in cytoskeletal rearrangement. Protein synthesis is controlled by ERK-1/2 via direct phosphorylation of $40 \mathrm{~S}$ ribosomal protein S6 kinase (S6K), which further phosphorylates the ribosomal protein S6 and stimulates the cap-dependent translation (62). Moreover, ERK-1/2 enhances the release of neurotransmitters via phosphorylation of synapsin-1, which docks the synaptic vesicles in the presynaptic space (63). ERK-1/2 also mediates anti-apoptotic effects via phosphorylation of Bad (64), caspase 9 (65), and GSK-3 $\beta$ (42).

\section{TrkB-mediated ERK activation}

BDNF activation of TrkB receptor also triggers ERK-1/2 pathway, via Ras, Raf and MEK. ERK-1/2 activity further mediates Arc gene expression and Arc mRNA transport to dendritic spines. Local Arc protein synthesis leads to formation of Arc/cofilin complexes, which reduce cofilin activity and thus promote actin polymerization and growth of dendritic spines (66). Cofilin phosphorylation at $\mathrm{S}^{3}$ also inhibits cofilin activity and enhances actin polymerization. The growth of the F-actin cytoskeleton transforms the active spines into big mushroom spines, which underlies the formation of long-term synaptic memory. In addition to the BDNF triggered PKB/ Akt activation of mTOR, which regulates the availability of eIF4E, ERK-1/2 activates Mnk1 kinase, which phosphorylates eIF4E at $\mathrm{S}^{209}(51)$. The latter phosphorylation is considered to be a rate limiting step in protein translation. Therefore BDNF controls both the availability and activity of translation factors via bifurcation of the biochemical cascades at Grb2 or Ras.

\section{BDNF-NMDAR POSITIVE FEEDBACK LOOPS}

NMDAR mediated prosurvival activity in many cases is believed to be result from autocrine BDNF secretion and subsequent activation of ERK-1/2 and PKB/Akt pathways (67). NMDAR activation at postsynaptic sites leads to activity dependent BDNF release from secretory granules in the postsynaptic neurons, mediating retrograde BDNF signaling in the synapse (68). However, electric activity also stimulates
BDNF transport along the axon, and subsequent release from the presynaptic terminals of cortical neurons (69). Both cited studies used overexpression of BDNF-GFP fusion protein and both studies reported co-existent axonal and dendritic localization of the BDNF secretory granules, therefore it is essential to assume that BDNF acts both as anterograde and retrograde synaptic messenger. Secreted BDNF acts both on presynaptic and postsynaptic TrkB receptors, either to facilitate neuromediator release presynaptically (63) or to contribute to postsynaptic LTP mediated by enhancement of NMDAR and L-type VGCC function (70). It is interesting to note however that NMDAR function does not only regulate the autocrine secretion of BDNF, it has been shown that basal level of intracellular $\mathrm{Ca}^{2+}$ gates the TrkB receptor function and the subsequent activation of the PI3K/Akt pathway via calmodulin (71). Conversely, BDNF rapidly augments glutamatergic synaptic transmission via enhanced activity of NR2B NMDARs (72). BDNF-activated TrkB receptors form macromolecular complexes with Fyn kinase and NR2B NMDARs, leading to NR2B phosphorylation and potentiation of the NR1/NR2B NMDAR-mediated $\mathrm{Ca}^{2+}$ influx. Fyn kinase attaches with its $\mathrm{SH} 2$ domain to the $\mathrm{C}$-terminal tail of NR2B NMDARs and phosphorylates tyrosine residues at three different sites - $\mathrm{Y}^{1252}, \mathrm{Y}^{1336}$ and $\mathrm{Y}^{1472}(21,73,74)$. Additionally, BDNF enhances NMDAR ionic currents by stabilization of microtubules and promotion of microtubule-dependent transport of NR2B subunits with their subsequent incorporation in the dendritic membrane (75). This completes a fast positive feedback loop between NMDAR and BDNF signaling (Fig.4) - NMDAR function leads to activity-dependent BDNF release from secretory granules and $\mathrm{Ca}^{2+}$-dependent gating of TrkB function, while BDNF-mediated TrkB activation potentiates NMDAR currents and controls the NMDAR insertion in the dendritic membrane.

There is a second much slower positive feedback loop at the level of gene transcription. Particularly it has been shown that synaptic NMDAR activity leads to enhanced CREB phosphorylation and BDNF gene expression $(32,76)$. NMDAR-mediated $\mathrm{Ca}^{2+}$ entry leads to decreased BDNF gene methylation (77) and upregulation of BDNF promoter III, via binding of pCREB, USF, and the novel $\mathrm{Ca}^{2+}$-responsive transcription factor $\mathrm{CaRF}(78,79)$ and derepresses the BDNF promoter IV activity, which is negatively regulated by BHLHB2 (80). NMDAR-activity regulated gene expression depends also on the NR1 subunit splice variants, and particularly on the inclusion of exon 21 encoding for the $\mathrm{C} 1$ cassette (81). 


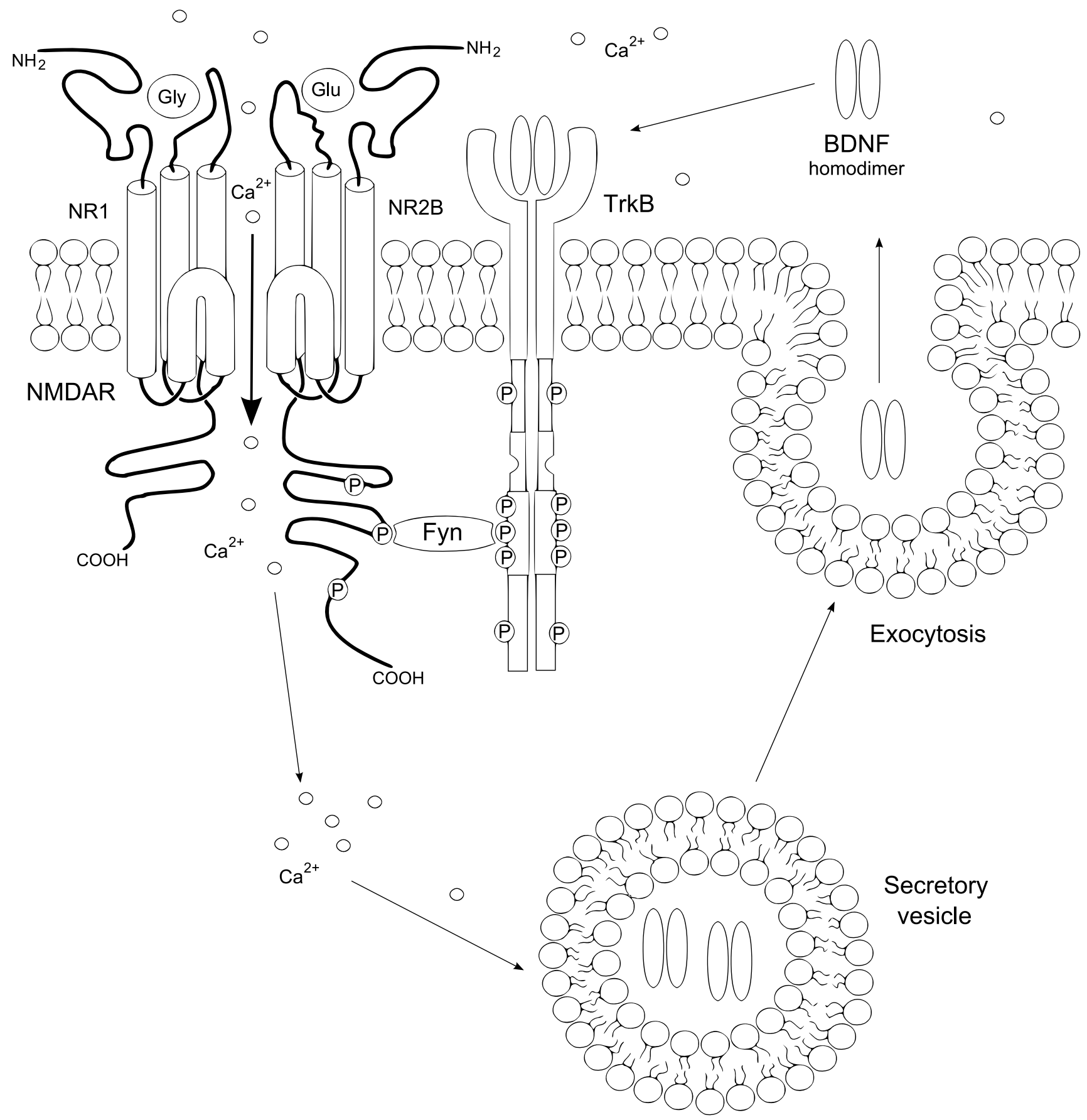

Figure 4. NMDAR-BDNF fast positive feedback loop. NMDAR activation leads to BDNF secretion from postsynaptic neurons, while BDNF enhances postsynaptic NMDAR currents via TrkB/Fyn/NR2B phosphorylation. 
Moreover, it has been shown that NMDAR activity leads to transport and accumulation of mRNA ${ }^{\mathrm{BNDF}}$ in distal dendrites, which accounts for local BDNF translation (82). Conversely, BDNF seems to be essential for NR2A but not NR2B subunit expression in cortex $(83,84)$, and interestingly in cerebellum BDNF promotes the replacement of NR2B with NR2C subunits during neuronal maturation (85).

\section{CONCLUDING REMARKS}

The existence of fast and slow positive feedback loops as well as existence of multiple crosstalk possibilities at all major biochemical pathways triggered by NMDA or BDNF makes it extremely difficult to delineate the relative contributions of classical neurotransmitters (glutamate) and neurotrophins (BDNF) in prosurvival signaling. Recent data suggests that neurotransmitters such as glutamate might have 'trophic' effects in central nervous system, while neurotrophins might act as 'neurotransmitters' having fast modulating effects on synaptic function. Thus neurotransmitters and neurotrophins operate in concert and have overlapping functions in vivo, and the smearing of boundaries between these two groups of signaling molecules reflects the rapid progress in neurosciences made in the past decade.

\section{ACKNOWLEDGEMENTS}

This work was supported by the Japanese Ministry of Education, Culture, Sports, Science and Technology (MEXT) awarding the prestigious Monbukagakusho scholarship to Danko Georgiev for the period 10/2005-09/2008 and grants-in-aid for promotion of scientific research aided to Yukio Yoneda.

\section{REFERENCES}

1. Blum R, Konnerth A. Neurotrophin-mediated rapid signaling in the central nervous system: mechanisms and functions. Physiology (Bethesda) 2005; 20: 70-78.

2. Ikonomidou C, Bosch F, Miksa M, Bittigau P, Vöckler $\mathrm{J}$, Dikranian K, et al. Blockade of NMDA receptors and apoptotic neurodegeneration in the developing brain. Science 1999; 283: 70-74.

3. Aarts M, Liu Y, Liu L, Besshoh S, Arundine M, Gurd JW, et al. Treatment of ischemic brain damage by perturbing NMDA receptor-PSD-95 protein interactions. Science 2002; 298: 846-850.

4. Taniura H, Iijima S, Kambe Y, Georgiev DD, Yoneda Y. Tex261 modulates the excitotoxic cell death induced by N-methyl-D-aspartate (NMDA) receptor activation.
Biochem Biophys Res Commun 2007; 362: 1096-1100.

5. Kambe Y, Nakamichi N, Georgiev DD, Nakamura N, Taniura H, Yoneda Y. Insensitivity to glutamate neurotoxicity mediated by NMDA receptors in association with delayed mitochondrial membrane potential disruption in cultured rat cortical neurons. J Neurochem 2008; 105 : 1886-1900.

6. Saarelainen T, Lukkarinen JA, Koponen S, Gröhn $\mathrm{OH}$, Jolkkonen J, Koponen E, et al. Transgenic mice overexpressing truncated TrkB neurotrophin receptors in neurons show increased susceptibility to cortical injury after focal cerebral ischemia. Mol Cell Neurosci 2000; 16: 87-96.

7. Balazs R. Trophic effect of glutamate. Curr Top Med Chem 2006; 6: 961-968.

8. Martel MA, Wyllie DJ, Hardingham GE. In developing hippocampal neurons, NR2B-containing N-methyl-Daspartate receptors (NMDARs) can mediate signaling to neuronal survival and synaptic potentiation, as well as neuronal death. Neuroscience 2009; 158: 334-343.

9. Georgiev DD, Taniura H, Kambe Y, Takarada T, Yoneda Y. A critical importance of polyamine site in NMDA receptors for neurite outgrowth and fasciculation at early stages of P19 neuronal differentiation. Exp Cell Res 2008; 314: 2603-2617.

10. Yoneyama M, Nakamichi N, Fukui M, Kitayama T, Georgiev DD, Makanga JO, et al. Promotion of neuronal differentiation through activation of N-methyl-D-aspartate receptors transiently expressed by undifferentiated neural progenitor cells in fetal rat neocortex. J Neurosci Res 2008; 86: 2392-2402.

11. Hwang JY, Kim YH, Ahn YH, Wie MB, Koh JY. NMethyl-D-aspartate receptor blockade induces neuronal apoptosis in cortical culture. Exp Neurol 1999; 159: 124130.

12. Tomitaka S, Tomitaka M, Tolliver BK, Sharp FR. Bilateral blockade of NMDA receptors in anterior thalamus by dizocilpine (MK-801) injures pyramidal neurons in rat retrosplenial cortex. Eur J Neurosci 2000; 12: 1420-1430.

13. Adams SM, de Rivero Vaccari JC, Corriveau RA. Pronounced cell death in the absence of NMDA receptors in the developing somatosensory thalamus. JNeurosci 2004; 24: 9441-9450.

14. Furukawa H, Singh SK, Mancusso R, Gouaux E. Subunit arrangement and function in NMDA receptors. Nature 2005; 438: 185-192.

15. Cull-Candy SG. NMDA receptors. Encyclopedia 
of Life Sciences, John Wiley and Sons, Inc., 2007; doi:10.1002/9780470015902.a0000254.pub2

16. Köhr G. NMDA receptor function: subunit composition versus spatial distribution. Cell Tissue Res 2006; 326: 439-446.

17. Bendel O, Meijer B, Hurd Y, von Euler G. Cloning and expression of the human NMDA receptor subunit NR3B in the adult human hippocampus. Neurosci Lett 2005; 377: 31-36.

18. Matsuda K, Fletcher M, Kamiya Y, Yuzaki M. Specific assembly with the NMDA receptor 3B subunit controls surface expression and calcium permeability of NMDA receptors. J Neurosci 2003; 23: 10064-10073.

19. Chatterton JE, Awobuluyi M, Premkumar LS, Takahashi $\mathrm{H}$, Talantova M, Shin Y, et al. Excitatory glycine receptors containing the NR3 family of NMDA receptor subunits. Nature 2002; 415: 793-798.

20. Suen PC, Wu K, Levine ES, Mount HT, Xu JL, Lin SY, et al. Brain-derived neurotrophic factor rapidly enhances phosphorylation of the postsynaptic N-methyl-D-aspartate receptor subunit 1. Proc Natl Acad Sci USA 1997; 94: 8191-8195.

21. Nakazawa T, Komai S, Tezuka T, Hisatsune C, Umemori $\mathrm{H}$, Semba K, et al. Characterization of Fyn-mediated tyrosine phosphorylation sites on GluRe2 (NR2B) subunit of the N-methyl-D-aspartate receptor. $J$ Biol Chem 2001; 276: 693-699.

22. Mizuno M, Yamada K, He J, Nakajima A, Nabeshima T. Involvement of BDNF receptor TrkB in spatial memory formation. Learn Mem 2003; 10: 108-115.

23. Tokumitsu H, Soderling TR. Requirements for calcium and calmodulin in the calmodulin kinase activation cascade. J Biol Chem 1996; 271: 5617-5622.

24. Yano S, Tokumitsu H, Soderling TR. Calcium promotes cell survival through CaMK kinase activation of the protein kinase B pathway. Nature 1998; 396: 584-587.

25. Braun AP, Schulman H. The multifunctional calcium/ calmodulin-dependent protein kinase: from form to function. Annu Rev Physiol 1995; 57: 417-445.

26. Bayer KU, De Koninck P, Leonard AS, Hell JW, Schulman $\mathrm{H}$. Interaction with the NMDA receptor locks CaMKII in an active conformation. Nature 2001; 411: 801-805.

27. Leonard AS, Bayer KU, Merrill MA, Lim IA, Shea MA, Schulman $\mathrm{H}$, et al. Regulation of calcium/calmodulindependent protein kinase II docking to N-methyl-Daspartate receptors by calcium/calmodulin and $\alpha$-actinin.
J Biol Chem 2002; 277: 48441-48448.

28. Sessoms-Sikes S, Honse Y, Lovinger DM, Colbran RJ. CaMKII $\alpha$ enhances the desensitization of NR2Bcontaining NMDA receptors by an autophosphorylationdependent mechanism. Mol Cell Neurosci 2005; 29: 139-147.

29. Hack N, Hidaka H, Wakefield MJ, Balázs R. Promotion of granule cell survival by high $\mathrm{K}^{+}$or excitatory amino acid treatment and $\mathrm{Ca}^{2+} /$ calmodulin-dependent protein kinase activity. Neuroscience 1993; 57: 9-20.

30. Lafon-Cazal M, Perez V, Bockaert J, Marin P. Akt mediates the anti-apoptotic effect of NMDA but not that induced by potassium depolarization in cultured cerebellar granule cells. Eur J Neurosci 2002; 16: 575-583.

31. Garoflos E, Stamatakis A, Mantelas A, Philippidis H, Stylianopoulou F. Cellular mechanisms underlying an effect of "early handling" on pCREB and BDNF in the neonatal rat hippocampus. Brain Res 2005; 1052: 187-195.

32. Hardingham GE, Fukunaga Y, Bading H. Extrasynaptic NMDARs oppose synaptic NMDARs by triggering CREB shut-off and cell death pathways. Nat Neurosci 2002; 5: 389-390.

33. Riccio A, Ginty DD. What a privilege to reside at the synapse: NMDA receptor signaling to CREB. Nat Neurosci 2002; 5: 389-390.

34. Tovar KR, Westbrook GL. Mobile NMDA receptors at hippocampal synapses. Neuron 2002; 34: 255-264.

35. Groc L, Bard L, Choquet D. Surface trafficking of N-methyl-D-aspartate receptors: Physiological and pathological perspectives. Neuroscience 2009; 158: 4-18.

36. Minichiello L, Calella AM, Medina DL, Bonhoeffer T, Klein R, Korte M. Mechanism of TrkB-mediated hippocampal long-term potentiation. Neuron 2002; 36: 121-137.

37. Farnsworth CL, Freshney NW, Rosen LB, Ghosh A, Greenberg ME, Feig LA. Calcium activation of Ras mediated by neuronal exchange factor Ras-GRF. Nature 1995; 376: 524-527.

38. Sutton G, Chandler LJ. Activity-dependent NMDA receptor-mediated activation of protein kinase B/Akt in cortical neuronal cultures. J Neurochem 2002; 82: 10971105.

39. Tian X, Gotoh T, Tsuji K, Lo EH, Huang S, Feig LA. Developmentally regulated role for Ras-GRFs in coupling NMDA glutamate receptors to Ras, Erk and CREB. EMBO $J$ 2004; 23: 1567-1575.

40. Toker A, Newton AC. Cellular signaling: pivoting around 
PDK-1. Cell 2000; 103: 185-188.

41. Stokoe D, Stephens LR, Copeland T, Gaffney PR, Reese $\mathrm{CB}$, Painter GF, et al. Dual role of phosphatidylinositol3,4,5-trisphosphate in the activation of protein kinase B. Science 1997; 277: 567-570.

42. Hetman M, Kharebava G. Survival signaling pathways activated by NMDA receptors. Curr Top Med Chem 2006; 6: 787-799.

43. Bramham CR, Messaoudi E. BDNF function in adult synaptic plasticity: the synaptic consolidation hypothesis. Prog Neurobiol 2005; 76: 99-125.

44. Marini AM, Paul SM. N-methyl-D-aspartate receptormediated neuroprotection in cerebellar granule cells requires new RNA and protein synthesis. Proc Natl Acad Sci USA 1992; 89: 6555-6559.

45. Leinninger GM, Backus C, Uhler MD, Lentz SI, Feldman EL. Phosphatidylinositol 3-kinase and Akt effectors mediate insulin-like growth factor-I neuroprotection in dorsal root ganglia neurons. FASEB J 2004; 18: 1544-1546.

46. Miao B, Yin XH, Pei DS, Zhang QG, Zhang GY. Neuroprotective effects of preconditioning ischemia on ischemic brain injury through down-regulating activation of JNK1/2 via N-methyl-D-aspartate receptor-mediated Akt1 activation. J Biol Chem 2005; 280: 21693-21699.

47. Zhang FX, Rubin R, Rooney TA. N-Methyl-D-aspartate inhibits apoptosis through activation of phosphatidylinositol 3-kinase in cerebellar granule neurons. A role for insulin receptor substrate- 1 in the neurotrophic action of N-methyl-D-aspartate and its inhibition by ethanol. J Biol Chem 1998; 273: 26596-26602.

48. Bhave SV, Ghoda L, Hoffman PL. Brain-derived neurotrophic factor mediates the anti-apoptotic effect of NMDA in cerebellar granule neurons: signal transduction cascades and site of ethanol action. JNeurosci 1999; 19: 3277-3286.

49. Xifro X, Malagelada C, Miñano A, Rodríguez-Alvarez J. Brief exposure to NMDA produces long-term protection of cerebellar granule cells from apoptosis. Eur J Neurosci 2005; $21: 827-840$.

50. Korte M, Minichiello L, Klein R, Bonhoeffer T. Shcbinding site in the TrkB receptor is not required for hippocampal long-term potentiation. Neuropharmacology 2000; 39: 717-724.

51. Soulé J, Messaoudi E, Bramham CR. Brain-derived neurotrophic factor and control of synaptic consolidation in the adult brain. Biochem Soc Trans 2006; 34: 600-604.

52. Atwal JK, Massie B, Miller FD, Kaplan DR. The TrkB-
Shc site signals neuronal survival and local axon growth via MEK and PI3-kinase. Neuron 2000; 27: 265-277.

53. Nedvetsky PI, Sessa WC, Schmidt HH. There's NO binding like NOS binding: protein-protein interactions in NO/cGMP signaling. Proc Natl Acad Sci USA 2002; 99: 16510-16512.

54. Yun HY, Dawson VL, Dawson TM. Glutamate-stimulated calcium activation of Ras/Erk pathway mediated by nitric oxide. Diabetes Res Clin Pract 1999; 45: 113-115.

55. Agell N, Bachs O, Rocamora N, Villalonga P. Modulation of the Ras/Raf/MEK/ERK pathway by $\mathrm{Ca}^{2+}$, and calmodulin. Cell Signal 2002; 14: 649-654.

56. Head BP, Patel HH, Tsutsumi YM, Hu Y, Mejia T, Mora $\mathrm{RC}$, et al. Caveolin-1 expression is essential for N-methyl-D-aspartate receptor-mediated Src and extracellular signal-regulated kinase $1 / 2$ activation and protection of primary neurons from ischemic cell death. FASEB J 2008; 22: 828-840.

57. Ivanov A, Pellegrino C, Rama S, Dumalska I, Salyha Y, Ben-Ari Y, et al. Opposing role of synaptic and extrasynaptic NMDA receptors in regulation of the extracellular signal-regulated kinases (ERK) activity in cultured rat hippocampal neurons. J Physiol 2006; 572: 789-798.

58. Hardingham GE. 2B synaptic or extrasynaptic determines signaling from the NMDA receptor. J Physiol 2006; 572: 614-615.

59. Zhu D, Wu X, Strauss KI, Lipsky RH, Qureshi Z, Terhakopian A, et al. N-methyl-D-aspartate and TrkB receptors protect neurons against glutamate excitotoxicity through an extracellular signal-regulated kinase pathway. $J \mathrm{Neu}$ rosci Res 2005; 80: 104-113.

60. Hetman M, GozdzA. Role of extracellular signal regulated kinases 1 and 2 in neuronal survival. Eur J Biochem 2004; 271: 2050-2055.

61. Sánchez C, Díaz-Nido J, Avila J. Phosphorylation of microtubule-associated protein 2 (MAP2) and its relevance for the regulation of the neuronal cytoskeleton function. Prog Neurobiol 2000; 61: 133-168.

62. Roux PP, Shahbazian D, Vu H, Holz MK, Cohen MS, Taunton $\mathrm{J}$, et al. RAS/ERK signaling promotes sitespecific ribosomal protein $\mathrm{S} 6$ phosphorylation via RSK and stimulates cap-dependent translation. J Biol Chem 2007; 282: 14056-14064.

63. Jovanovic JN, Czernik AJ, Fienberg AA, Greengard P, Sihra TS. Synapsins as mediators of BDNF-enhanced neurotransmitter release. Nat Neurosci 2000; 3: 323-329. 
64. Jin K, Mao XO, Zhu Y, Greenberg DA. MEK and ERK protect hypoxic cortical neurons via phosphorylation of Bad. J Neurochem 2002; 80: 119-125.

65. Allan LA, Morrice N, Brady S, Magee G, Pathak S, Clarke PR. Inhibition of caspase-9 through phosphorylation at Thr 125 by ERK MAPK. Nat Cell Biol 2003; 5: 647-654.

66. Messaoudi E, Kanhema T, Soulé J, Tiron A, Dagyte G, da Silva B, et al. Sustained Arc/Arg3.1 synthesis controls long-term potentiation consolidation through regulation of local actin polymerization in the dentate gyrus in vivo. J Neurosci 2007; 27: 10445-10455.

67. Jiang X, Tian F, Mearow K, Okagaki P, Lipsky RH, Marini AM. The excitoprotective effect of N-methyl-D-aspartate receptors is mediated by a brain-derived neurotrophic factor autocrine loop in cultured hippocampal neurons. $J$ Neurochem 2005; 94: 713-722.

68. Hartmann M, Heumann R, Lessmann V. Synaptic secretion of BDNF after high-frequency stimulation of glutamatergic synapses. EMBO J 2001; 20: 5887-5897.

69. Kohara K, Kitamura A, Morishima M, Tsumoto T. Activity-dependent transfer of brain-derived neurotrophic factor to postsynaptic neurons. Science 2001; 291: 2419-2423.

70. Kovalchuk Y, Hanse E, Kafitz KW, Konnerth A. Postsynaptic induction of BDNF-mediated long-term potentiation. Science 2002; 295: 1729-1734.

71. Zheng F, Soellner D, Nunez J, Wang H. The basal level of intracellular calcium gates the activation of phosphoinositide 3-kinase-Akt signaling by brain-derived neurotrophic factor in cortical neurons. $J$ Neurochem 2008; 106: 1259-1274.

72. Crozier RA, Black IB, Plummer MR. Blockade of NR2Bcontaining NMDA receptors prevents BDNF enhancement of glutamatergic transmission in hippocampal neurons. Learn Mem 1999; 6: 257-266.

73. Takagi N, Cheung HH, Bissoon N, Teves L, Wallace MC, Gurd JW. The effect of transient global ischemia on the interaction of Src and Fyn with the N-methyl-D-aspartate receptor and postsynaptic densities: possible involvement of Src homology 2 domains. J Cereb Blood Flow Metab 1999; 19: 880-888.

74. Ryan TJ, Emes RD, Grant SG, Komiyama NH. Evolution of NMDA receptor cytoplasmic interaction domains: implications for organisation of synaptic signaling com- plexes. BMC Neurosci 2008; 9: 6.

75. Yuen EY, Jiang Q, Feng J, Yan Z. Microtubule regulation of N-methyl-D-aspartate receptor channels in neurons. $J$ Biol Chem 2005; 280: 29420-29427.

76. Chen M, Lu TJ, Chen XJ, Zhou Y, Chen Q, Feng XY, et al. Differential roles of NMDA receptor subtypes in ischemic neuronal cell death and ischemic tolerance. Stroke 2008; 39: 3042-3048.

77. Lubin FD, Roth TL, Sweatt JD. Epigenetic regulation of BDNF gene transcription in the consolidation of fear memory. J Neurosci 2008; 28: 10576-10586.

78. Ou LC, Gean PW. Transcriptional regulation of brainderived neurotrophic factor in the amygdala during consolidation of fear memory. Mol Pharmacol 2007; 72: 350-358.

79. Tabuchi A. Synaptic plasticity-regulated gene expression: a key event in the long-lasting changes of neuronal function. Biol Pharm Bull 2008; 31: 327-335.

80. Jiang X, Tian F, Du Y, Copeland NG, Jenkins NA, Tessarollo L, et al. BHLHB2 controls BDNF promoter 4 activity and neuronal excitability. $J$ Neurosci 2008; 28: 1118-1130.

81. Bradley J, Carter SR, Rao VR, Wang J, Finkbeiner S. Splice variants of the NR1 subunit differentially induce NMDA receptor-dependent gene expression. $J$ Neurosci 2006; 26: 1065-1076.

82. Tongiorgi E, Baj G. Functions and mechanisms of BDNF mRNA trafficking. Novartis Found Symp 2008; 289: 136147.

83. Small DL, Murray CL, Mealing GA, Poulter MO, Buchan AM, Morley P. Brain derived neurotrophic factor induction of N-methyl-D-aspartate receptor subunit NR2A expression in cultured rat cortical neurons. Neurosci Lett 1998; 252: 211-214.

84. Margottil E, Domenici L. NR2A but not NR2B N-methyl$\mathrm{D}$-aspartate receptor subunit is altered in the visual cortex of BDNF-knock-out mice. Cell Mol Neurobiol 2003; 23: 165-174.

85. Suzuki K, Sato M, Morishima Y, Nakanishi S. Neuronal depolarization controls brain-derived neurotrophic factor-induced upregulation of NR2C NMDA receptor via calcineurin signaling. $J$ Neurosci 2005; 25: 9535-9543. 